\title{
Innovative Concept for the Recovery of Silver and Indium by a Combined Treatment of Jarosite and Electric Arc Furnace Dust
}

\author{
S. WEGSCHEIDER, ${ }^{1,2}$ S. STEINLECHNER, ${ }^{1,3}$ \\ and M. LEUCHTENMÜLLER ${ }^{1}$
}

1.-Chair of Nonferrous Metallurgy, Montanuniversitaet Leoben, 8700 Leoben, Austria. 2.—e-mail: stefan.wegscheider@unileoben.ac.at. 3.—e-mail: stefan.steinlechner@unileoben.ac.at

Industrial wastes such as slags, dust, or precipitation residues contain significant amounts of valuable metals like zinc, lead, and copper as well as precious metals like silver and indium. Nevertheless, a lot of these waste materials are not recycled, and therefore, many valuable metals end up being sent to landfills. Because of harmful components in the waste, it is often necessary to send it to specialized landfills for hazardous wastes, which leads to environmental problems as well as additional costs. Consequently, the recovery of the valuable metals from the residues represents a sensible task to decrease the negative impact on the environment and to reduce costs for maintaining a landfill. In addition, recycling helps to decrease the dependency from primary resources. The present study deals with the behavior of different metals in a pyro-metallurgical treatment for a mixture of jarosite and electric arc furnace dust with a special focus on indium and silver.

\section{INTRODUCTION}

Indium is only produced as a by-product with other metals like zinc, lead, or tin. With a share of about $95 \%$, the zinc industry constitutes the main source for the production of indium, through mainly processing sphalerite. In 2009, 150 million tons of ore containing between 1500 tons and 1600 tons of indium were mined. ${ }^{1}$ With an annual production of around 500 tons, the recovery rate from ores only reached $35 \%$, which is why $65 \%$ of the mined indium ends up in landfills. Although the zinc production will increase by an annual growth rate of approximately $1 \%-3 \%$, the predicted growth rate for indium sums up to $15 \%$ per year. ${ }^{2}$ Therefore, it is necessary to increase the recovery rates of indium to meet the demand in the coming decades. The most important area of application is represented by indium-tin-oxides, which are used as transparent conductors in displays. ${ }^{3,4}$ Figure 1 shows the indium production from 1994 to 2013 and highlights that the largest proportion derives from China. Other important producers include South Korea, Canada, Japan, France, and Belgium. ${ }^{5}$ The average growth rate from 1994 to 2013 reached almost $10 \%$. At the same time, the zinc ore production increased from $6.8 \mathrm{Mt} / \mathrm{a}$ to $13.4 \mathrm{Mt} / \mathrm{a}$, which represents an average growth rate of $3.8 \%$.
As already described, the indium production almost completely depends on the zinc industry because at the moment there is no direct production of indium from primary ores. In contrast, the production routes of silver are numerous. The main sources for silver derive from the lead, copper, and gold industry from the production facilities all over the world. The biggest mine supplier in 2013 was South America with 7471 tons, followed by North America with 7013 tons, Asia with 5326 tons, and Europe with 3270 tons. At the same time, Australia and Africa together produced 2318 tons (see Fig. 2). ${ }^{8}$ Silver is mainly used for coins as a conductor in electrical components and for jewelry. ${ }^{9}$

To conclude, this market overview shows that the supply for indium may be critical because of its dependency from the zinc production. The situation for silver is significantly better, but obviously the recovery of silver can help to make the recovery process more profitable.

This article examines the behavior of silver and indium and its possible recovery in a pyro-metallurgical treatment of a mixture of jarosite and electric arc furnace dust (EAFD). Jarosite represents a residue formed during the iron removal in the hydro-metallurgical zinc winning process, containing indium and silver. The precipitation of iron 
is necessary because a certain part of the zinc in the ore reacts to zinc ferrite during the roasting step and is therefore only soluble in strongly acidic solutions. During the so called hot-acid-leaching (temperatures of $90^{\circ} \mathrm{C}$ and acid concentrations of $120 \mathrm{~g} \mathrm{H}_{2} \mathrm{SO}_{4} / \mathrm{l}$ ), zinc ferrite dissolves and zinc and iron enter the solution. Because iron would badly

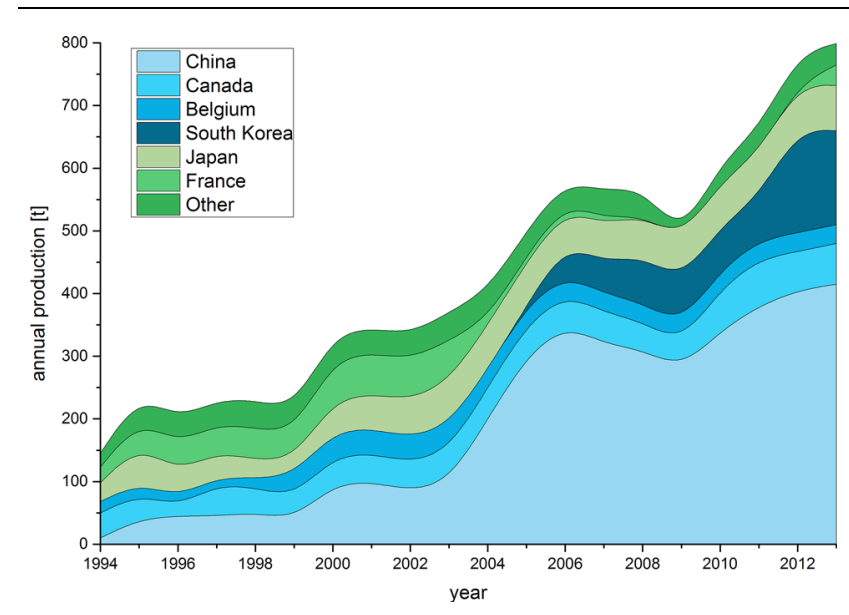

Fig. 1. Indium production from 1994 to 2013.

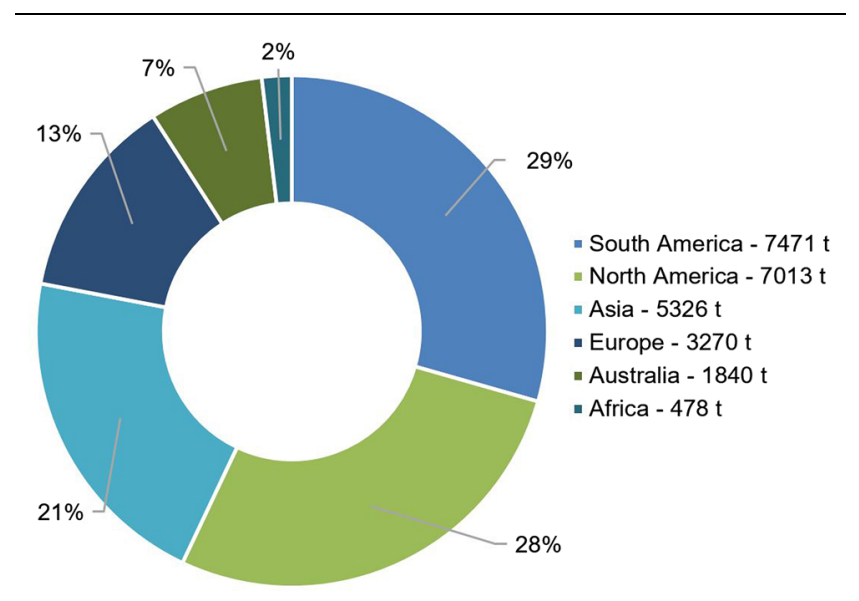

Fig. 2. Silver mine production in 2013. affect the electrolysis, its removal is mandatory. EAFD on the other side is a residue formed during the remelting of steel scrap in an electric arc furnace. Typical elements include zinc, lead, iron, chlorine, and fluorine in this type of dust.

\section{CHARACTERIZATION AND THERMODYNAMIC CALCULATIONS}

Generally, a detailed characterization and thermodynamic calculations form the base to develop a new recycling concept. In Table I, the analyses of jarosite and EAFD are listed.

The main elements in the present jarosite are iron, zinc, lead, and sulfur. Silver and indium can be found in relatively high concentrations reaching $180 \mathrm{ppm}$ and $230 \mathrm{ppm}$, respectively. In EAFD, iron, lead, and zinc are also contained, yet in different concentrations. The high zinc content is caused by remelting galvanized steel plates in the electric arc furnace. Compared with jarosite, the sulfur yield is relatively low; however, the values for chlorine and fluorine are high as a result of flame retardants, synthetic coatings, etc. from the scrap.

Several thermodynamic calculations were carried out with the software HSC Chemistry 8 from the company Outotec. The results show that indium and silver are nonvolatile neither as metals nor as oxides, which is why oxidizing or reducing conditions on their own are insufficient. Therefore, some additives besides reducing conditions are necessary to transform indium and silver into chlorides that are volatile at relatively low temperatures. These findings lead to EAFD because this dust can act as a source for chlorine. The advantages are no dumping of the dust and no need for other additives (cost savings). For the experimental part, mass balances were also calculated to find out what ratio of EAFD to jarosite should be applied for the different test series.

\section{EXPERIMENTAL}

The whole laboratory-scale experiment series included tests with different parameters. The ratio of the amount of jarosite to EAFD always remained

Table I. Chemical analysis of the main elements of the investigated jarosite and EAFD

\begin{tabular}{|c|c|c|c|c|c|}
\hline \multicolumn{3}{|l|}{ Jarosite } & \multicolumn{3}{|c|}{ EAFD } \\
\hline Element & Concentration (wt.\%) & Method & $\underline{\text { Element }}$ & Concentration (wt.\%) & Method \\
\hline $\mathrm{Ag}$ & 0.018 & DIN EN ISO 11885 & $\mathrm{Ag}$ & - & - \\
\hline In & 0.023 & DIN EN ISO 11885 & In & - & - \\
\hline $\mathrm{Fe}$ & 27.1 & DIN EN ISO 11885 & $\mathrm{Fe}$ & 17.3 & DIN EN ISO 11885 \\
\hline $\mathrm{Zn}$ & 6.5 & DIN EN ISO 11885 & $\mathrm{Zn}$ & 37.2 & DIN EN ISO 11885 \\
\hline $\mathrm{Pb}$ & 6.2 & DIN EN ISO 11885 & $\mathrm{~Pb}$ & 2.95 & DIN EN ISO 11885 \\
\hline $\mathrm{S}$ & 8.4 & DIN EN ISO 15350 & $\mathrm{~S}$ & 0.44 & DIN EN ISO 15350 \\
\hline $\mathrm{Cl}$ & $<0.1$ & DIN 38405 D1-2 & $\mathrm{Cl}$ & 4.9 & DIN 38405 D1-2 \\
\hline $\mathrm{F}$ & 0.01 & DIN 38405 Teil1 & $\mathrm{F}$ & 0.36 & DIN 38405 Teil1 \\
\hline
\end{tabular}


Table II. Experimental design

\begin{tabular}{|c|c|c|c|c|c|}
\hline \multicolumn{3}{|l|}{ Campaign 1} & \multicolumn{3}{|l|}{ Campaign 2} \\
\hline Input material & $\begin{array}{c}\text { Temperature } \\
\left({ }^{\circ} \mathrm{C}\right)\end{array}$ & $\begin{array}{l}\text { Time } \\
\text { (min) }\end{array}$ & Input material & $\begin{array}{c}\text { Temperature } \\
\left({ }^{\circ} \mathrm{C}\right)\end{array}$ & $\begin{array}{l}\text { Time } \\
(\text { min) }\end{array}$ \\
\hline Jarosite raw + EAFD & 900 & 30 & Jarosite raw + EAFD + reduction agent & 900 & 30 \\
\hline Jarosite raw + EAFD & 900 & 60 & Jarosite raw + EAFD + reduction agent & 900 & 60 \\
\hline Jarosite roasted + EAFD & 900 & 30 & Jarosite roasted + EAFD + reduction agent & 900 & 30 \\
\hline Jarosite roasted + EAFD & 900 & 60 & Jarosite roasted + EAFD + reduction agent & 900 & 60 \\
\hline Jarosite raw + EAFD & 1000 & 30 & Jarosite raw + EAFD + reduction agent & 1000 & 30 \\
\hline Jarosite raw + EAFD & 1000 & 60 & Jarosite raw + EAFD + reduction agent & 1000 & 60 \\
\hline Jarosite roasted + EAFD & 1000 & 30 & Jarosite roasted + EAFD + reduction agent & 1000 & 30 \\
\hline Jarosite roasted + EAFD & 1000 & 60 & Jarosite roasted + EAFD + reduction agent & 1000 & 60 \\
\hline Jarosite raw + EAFD & 1100 & 30 & Jarosite raw + EAFD + reduction agent & 1100 & 30 \\
\hline Jarosite raw + EAFD & 1100 & 60 & Jarosite raw + EAFD + reduction agent & 1100 & 60 \\
\hline Jarosite roasted + EAFD & 1100 & 30 & Jarosite roasted + EAFD + reduction agent & 1100 & 30 \\
\hline Jarosite roasted + EAFD & 1100 & 60 & Jarosite roasted + EAFD + reduction agent & 1100 & 60 \\
\hline
\end{tabular}
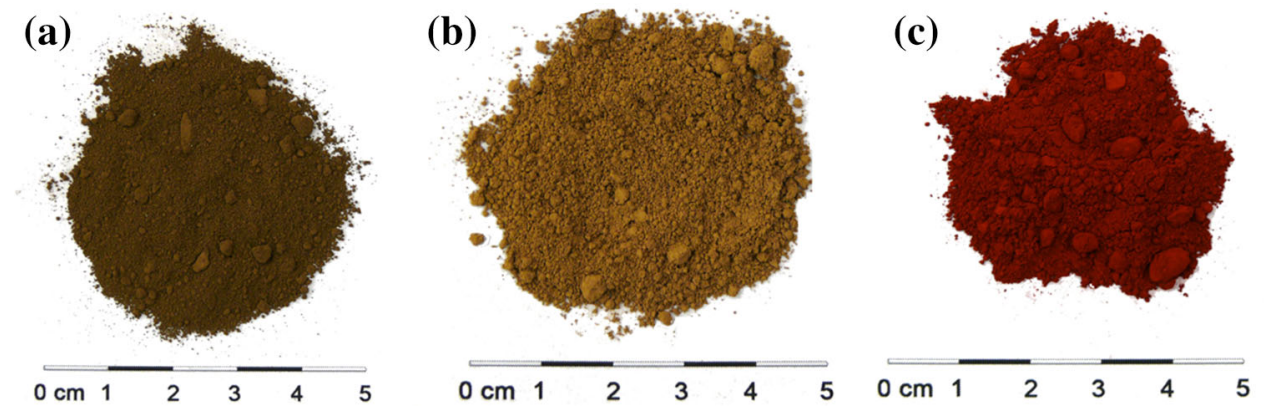

Fig. 3. Input materials EAFD (a), jarosite raw (b), and jarosite roasted (c).

the same; however, in half of the cases, the addition of a reducing agent was evaluated and in another half the jarosite experienced a pretreatment. The stoichiometric amount of the reducing agent to reduce the desired compounds was calculated by mass balances. Different temperatures and residence times should show the influence on the volatilization behavior. Findings from thermodynamic calculations showed that a temperature above $900^{\circ} \mathrm{C}$ can be sufficient for a selective vaporization; therefore, the test series were performed at $900^{\circ} \mathrm{C}, 1000^{\circ} \mathrm{C}$, and $1100^{\circ} \mathrm{C}$. The residence time was $30 \mathrm{~min}$ and $60 \mathrm{~min}$. Every trial contained eight ceramic ships (dimensions of one ship: $120 \times 30 \times 16 \mathrm{~mm}$ ), where four represented reference ships. Table II gives an overview of the realized experiments.

The experimental part started with a preparation of the input materials. The precipitation residue jarosite is high in its moisture content; therefore, it was dried at $120^{\circ} \mathrm{C}$ for $48 \mathrm{~h}$. The mass loss reached about $25 \%$. Afterward the material was transferred into a vibrating tube mill to pulverize the dried jarosite. This material was designated as "jarosite raw." Since jarosite is high in its sulfur content, a pretreatment at $650^{\circ} \mathrm{C}$ for $3 \mathrm{~h}$ leads to a decomposition of sulfates and, hence, to a removal of sulfur ("jarosite roasted"). The material also gets milled in a vibrating tube mill. To see possible differences between a pretreated jarosite and a raw jarosite, the examinations were done with both types. The last input material is EAFD, which also gets milled to a fine fraction. In Fig. 3, all three input materials can be seen.

For all examinations, the ingredients were mixed well at a certain ratio (EAFD:jarosite $=3: 2$ ) to get a homogeneous input material. The pyrometallurgical investigations were carried out in a muffle furnace in small ceramic ships as pictured in Fig. 4. The ships were filled with a defined weight of the different mixtures before they entered the furnace.

After the heat treatment, the ships were removed from the furnace and cooled by air before being analyzed. The oxidizing atmosphere during cooling has no influence on the final silver and indium recovery, as the reducing conditions in the ceramic boats during the treatment should only enable the reaction to form a volatile compound. 


\section{EXPERIMENTAL RESULTS}

As a result of the low weight of the mixture per sample, it was not possible to analyze the vaporized dust. The weight of the remaining material in the
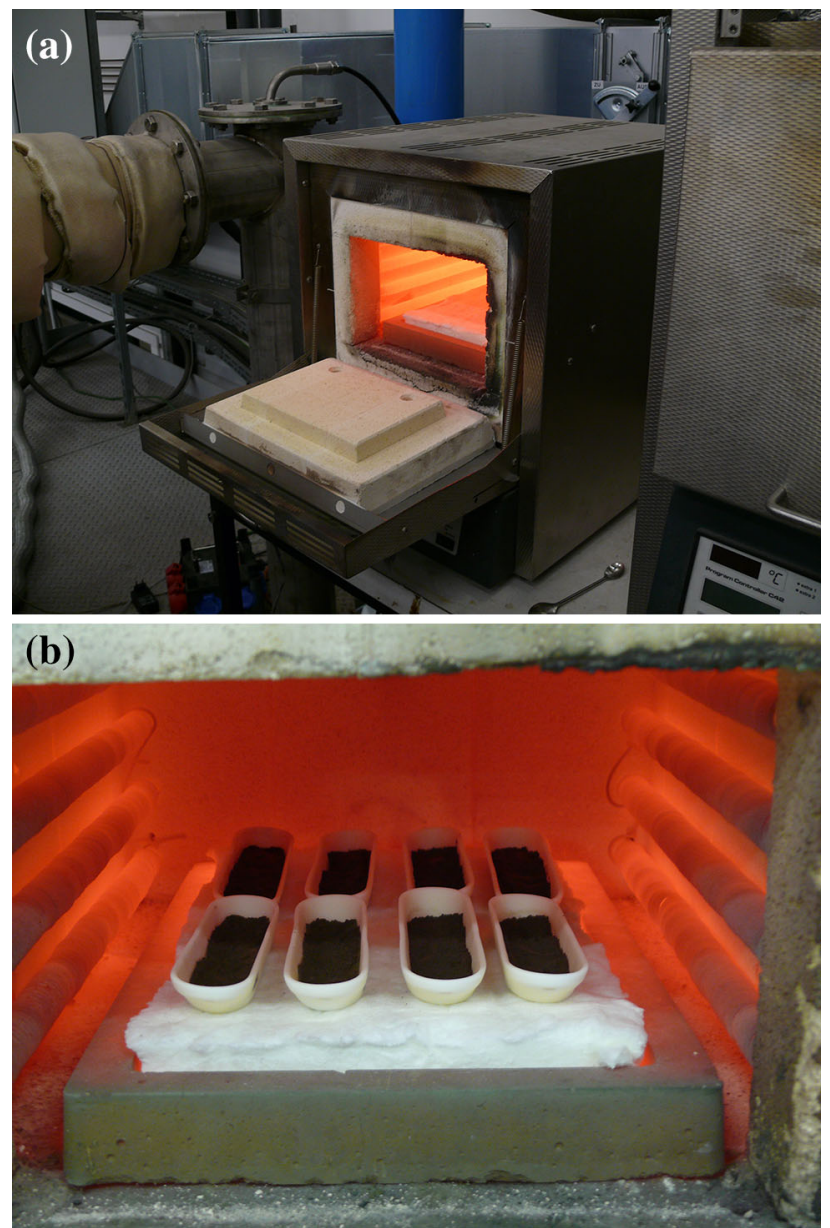

Fig. 4. Small muffle furnace (a) and ceramic ships in the furnace (b). ceramic ship and the analysis of this residue displays the result for the recovery rates, which can be calculated with the following formula (1):

recovery rate $_{x}[\%]=100-\frac{\left(m_{\text {input }} \times \frac{[\%]_{x \text { input }}}{100}\right)}{\left(m_{\text {output }} \times \frac{[\%]_{x \text { output }}}{100}\right)} \times 100$

Figure 5 shows exemplarily the mixture of jarosite and EAFD before and after the pyrometallurgical treatment in the muffle furnace.

The two graphs in Fig. 6 illustrate the difference between the general mass loss with and without a reducing agent. In campaign 1 , no reductive was used, whereas campaign 2 included Desulco (brand name) graphite in the mixture.

The higher the temperature of the treatment gets, the higher is the mass loss of the treated material. In general, the loss in campaign 1 is lower than in campaign 2 . In both graphs, the higher tendency for vaporization of "jarosite raw" is apparent because the treated jarosite already loses its sulfates in the pretreatment step. No significant difference is evident when considering the residence time of all samples. To have a better comparability of the overall mass loss of campaign 1 and 2 , the formed carbon monoxide, in case of addition of reducing agent, was deducted in campaign 2 .

In Fig. 7, the different recovery (evaporation) rates for silver of both campaigns are displayed. In campaign 1 without a reductant, the removal of silver cannot be achieved at $900^{\circ} \mathrm{C}$. Nevertheless, in campaign 2 , with a reducing agent, recovery rates of $67 \%-79 \%$ can be reached at the same temperature. In Fig. $7 \mathrm{a}$, the influence of the residence time is only visible at $1000^{\circ} \mathrm{C}$. The longer the treatment is, the higher is the recovery rate. At $1100^{\circ} \mathrm{C}$, all mixtures of both campaigns achieve a recovery rate of more than $80 \%$. The residual content of silver in the (a)

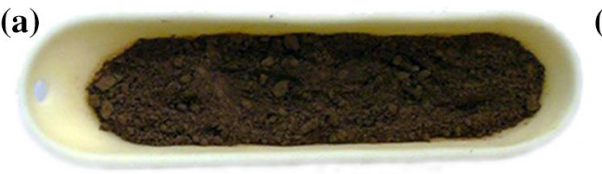

(b)

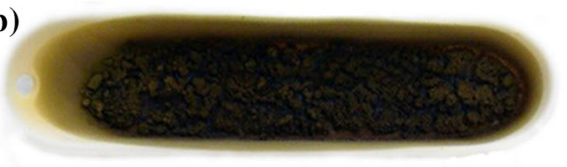

Fig. 5. Mixture of jarosite and EAFD before (a) and after (b) the pyrometallurgical treatment. 

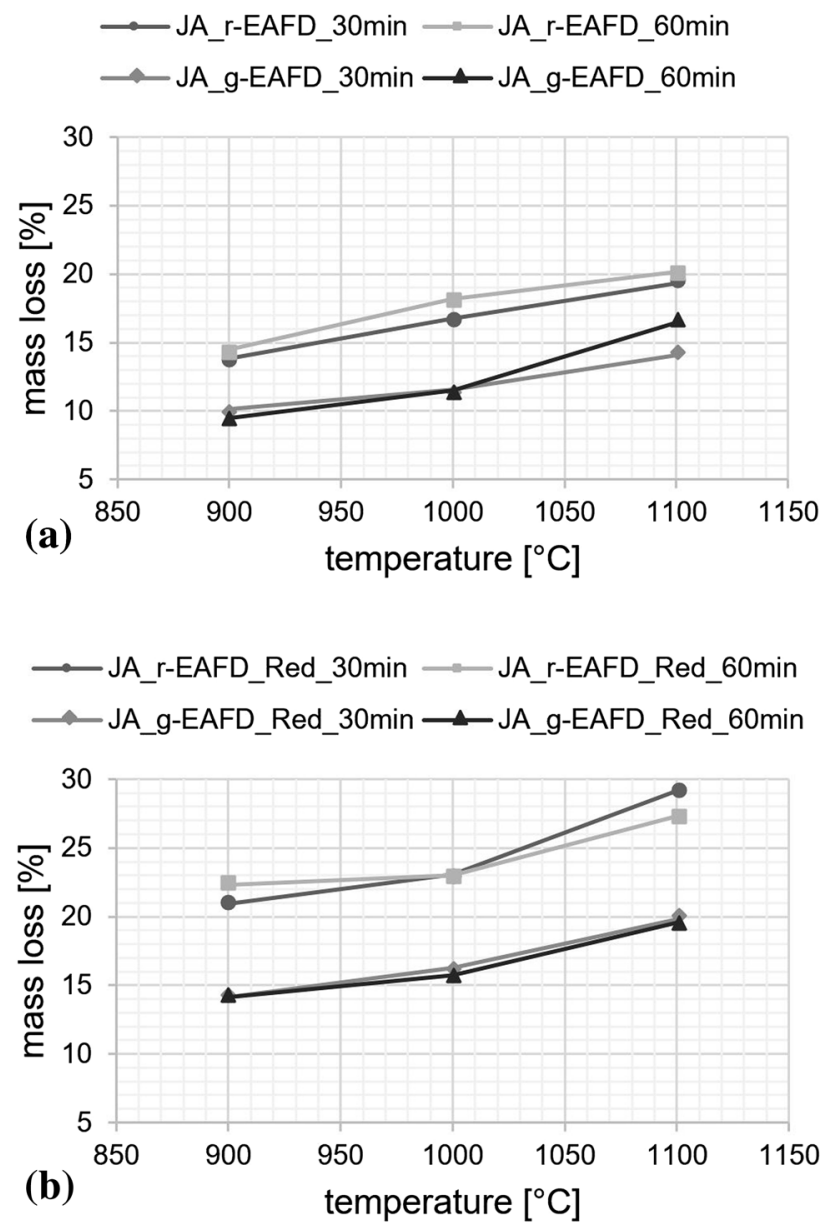

Fig. 6. Different evaporation rate campaign 1 (a) and campaign 2 (b).

mixture "JA_g-EAFD-1100_60 min", "JA_r-EAFD_ Red_1000_60 min", "JA_g-EAFD_Red_1000_60 min", and "JA_r-EAFD_Red_1100_60 min" was beneath the analysis limits, and hence, even higher recovery rates of more than $90 \%$ were reached but are not shown in the graphs. The same graphs for indium are outlined in Fig. 8.

These figures explain the behavior of indium, which in contrast to silver is completely different. Without any carbon, the possibility of removing indium in the gas phase is not given at any investigated temperature. Only campaign 2 at $1100^{\circ} \mathrm{C}$ shows success regarding a volatilization of indium
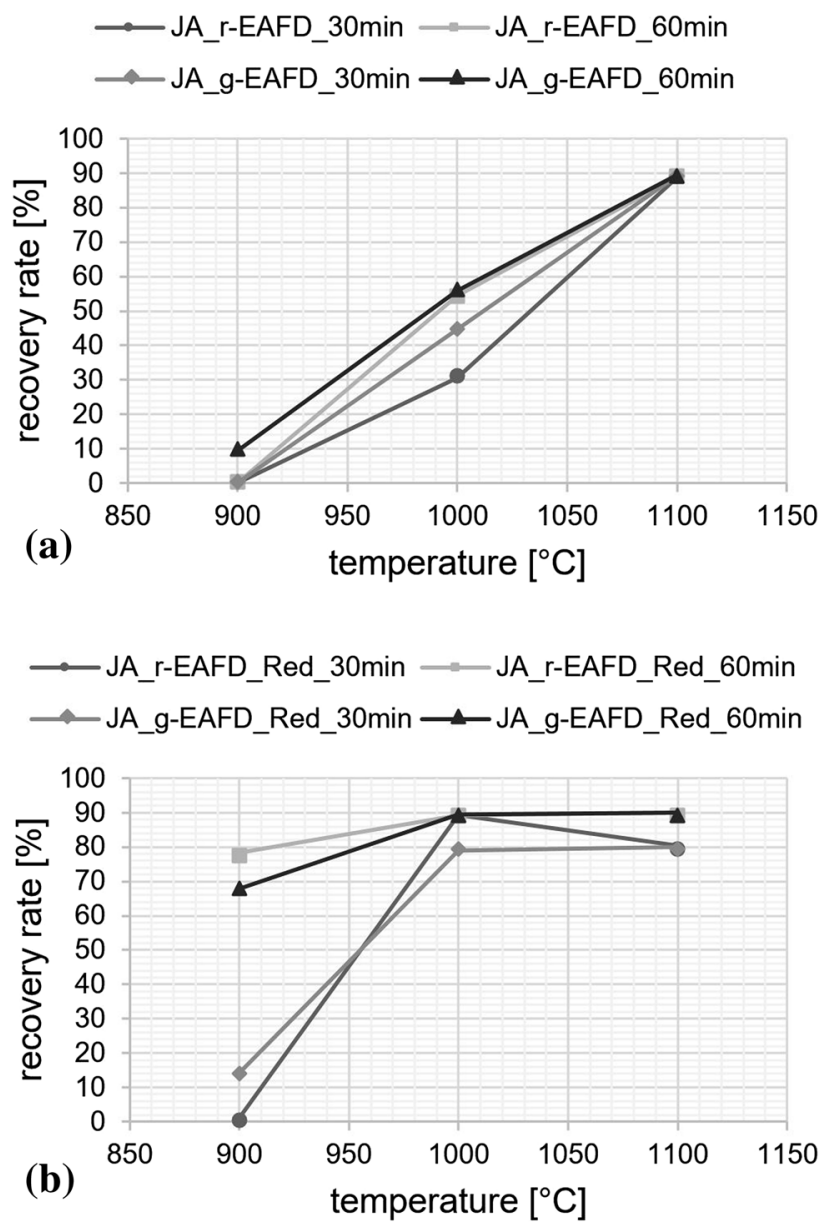

Fig. 7. Different recovery rates for silver in campaign 1 (a) and campaign 2 (b).

with recovery rates between $53 \%$ and $56 \%$. Neither an influence of the residence time nor an influence of a pretreatment of the jarosite can be detected.

The two trials at $1100^{\circ} \mathrm{C}$ with addition of a reducing agent, which are listed in Table III, show the best results concerning silver and indium recovery. In addition to indium and silver, some other recovery rates for selected metals are displayed.

Iron seems to be the most stable examined element in the mixture. The evaporation rate for zinc is relatively low, although metallic zinc is easy to volatile at temperatures above $900^{\circ} \mathrm{C}$. Lead and 
sulfur reach more than a $91 \%$ recovery rate. Silver seems to volatilize easily beside chlorine and fluorine. As mentioned, the recovery rate for silver in one case exceeds $90 \%$ because the analysis limit for silver (silver content in the remaining material

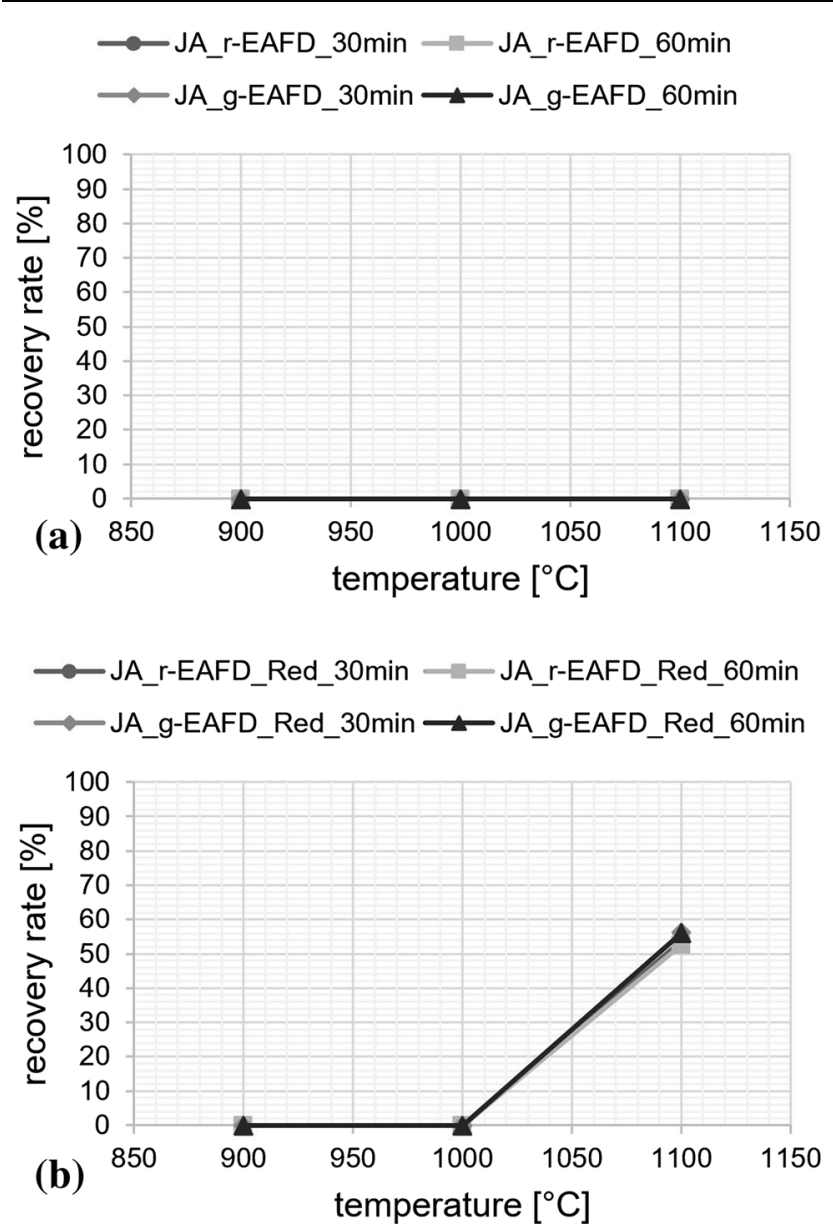

Fig. 8. Different recovery rates for indium in campaign 1 (a) and campaign 2 (b). was $<0.001 \%$ ) is reached. As expected from the thermodynamic calculations, around $53 \%-56 \%$ of the indium are vaporized under reducing conditions.

\section{CONCLUSION}

As a result of environmental problems caused by dumped material, high costs for maintaining a landfill, dependency from raw materials, and the necessity to meet the demand in the coming decades for metals like indium, the recovery of residues gets more and more important. In most cases, the efficiency of developed recycling processes is poor, and therefore, these processes often are not economical. Minor elements such as indium and silver contained and recovered from jarosite can increase the economics of a possible recycling process. Furthermore, several advantages can be mentioned for combining EAFD with jarosite: Two residues can be treated together to recover valuable metals, no more dumping of the dust and no need for addition of other additives (possible cost savings). Based on thermodynamic calculations and extensive chemical analyses, test series were performed in a small muffle furnace with ceramic ships. The results showed that silver as well as indium can be recovered best by a volatilization treatment under reducing conditions at temperatures of $1100^{\circ} \mathrm{C}$. The pretreatment of the jarosite shows no significant influence on the results; however, the formation of off-gas as a result of the high sulfur content in the raw jarosite may lead to problems on a bigger scale. To save energy, no pretreatment is the aim.

The next step will be to verify these practical findings by performing a pyrometallurgical test series under the same conditions on a bigger scale. Furthermore, some kinetic investigations are planned to maximize the volatilization of indium and silver and to improve the recovery for zinc to enable a multimetal recovery.

Table III. Recovery rates for selected elements at $1100^{\circ} \mathrm{C}$

\begin{tabular}{|c|c|c|c|c|c|c|c|c|}
\hline Sample & Ag & In & $\mathbf{F e}$ & Zn & $\mathbf{P b}$ & $\mathbf{S}$ & Cl & $\mathbf{F}$ \\
\hline JA_r-EAFD_Red_1100_60 min & $>89.95$ & 52.61 & 3.09 & 12.81 & 95.04 & 97.79 & 99.75 & 96.04 \\
\hline JA_g-EAFD_Red_1100_60 min & 89.95 & 56.02 & 0.92 & 12.22 & 91.64 & 96.12 & 99.73 & 96.28 \\
\hline
\end{tabular}

All values in (\%). 


\section{ACKNOWLEDGEMENT}

Open access funding provided by Montanuniversität Leoben. The authors want to thank the Austrian Research Promotion Agency (FFG) and the Federal Ministry of Science, Research and Economy (BMWFW) for the financial support.

\section{OPEN ACCESS}

This article is distributed under the terms of the Creative Commons Attribution 4.0 International License (http://creativecommons.org/licenses/by/4.0/), which permits unrestricted use, distribution, and reproduction in any medium, provided you give appropriate credit to the original author(s) and the source, provide a link to the Creative Commons license, and indicate if changes were made.

\section{REFERENCES}

1. M. Liedtke and D. Homberg-Heumann, By-product Elements and Coupled El-ements, POLINARES Working Paper 18 (European Community Project, 2012).
2. C. Gibson and T. Hayes, Indium and Gallium overview, http://www.edisoninvestmentresearch.com/sectorreports/ IndiumGalliumOverview071011.pdf. Accessed 19 October 2016 .

3. U.S. Geological Survey, Metal Prices in the United States Through 2010, http://pubs.usgs.gov/sir/2012/5188/sir20125188.pdf. Accessed 19 October 2016.

4. U.S. Geological Survey, 2012 Minerals Yearbook-Indium, http://minerals.usgs.gov/minerals/pubs/commodity/indium/ myb1-2012-indiu.pdf. Accessed 19 October 2016.

5. U.S. Geological Survey, Mineral Commodity Summaries 2014, http://minerals.usgs.gov/minerals/pubs/mcs/2014/ mcs2014.pdf. Accessed 19 October 2016.

6. S.M. Jasinski, Zinc, http://minerals.usgs.gov/minerals/ pubs/commodity/zinc/720494.pdf. Accessed 19 October 2016.

7. U.S. Geological Survey, Mineral Commodity Summaries 2015, http://minerals.usgs.gov/minerals/pubs/mcs/2015/ mcs2015.pdf. Accessed 19 October 2016.

8. The Silver Institute, World Silver Survey 2014, http://www. mineralinfo.fr/sites/default/files/upload/documents/worldsil versurvey-2014_silverinstitute.pdf. Accessed 19 October 2016.

9. E.C. Ferré, The Many Uses of Silver, http://geology.com/ articles/uses-of-silver/. Accessed 19 October 2016. 